\title{
A MODEL SIMULATION OF THE SOLAR ENERGY IMPINGING ON THE GIZA PYRAMIDS
}

\author{
Camuffo, D. \\ National Research Council (CNR), Institute of Atmospheric Sciences and Climate (ISAC), Padua, Italy \\ E-mail:d.camuffo@isac.cnr.it
}

\begin{abstract}
A simulation model of the solar energy impinging on stone blocks is made to ascertain the impact of solar radiation on the walls of the Pyramids of Giza, Egypt. The model considers the solar radiation hitting the upper surface, and the vertical sides of stone blocks on the four walls. The calculation concerns: the solar height and azimuth; the daily total amount of solar radiation; the instantaneous values of the flux of solar radiation. The results are reported and discussed, pointing out the main features of the daily and seasonal cycles, as well as the impact on the various exposures.
\end{abstract}

Keywords: Physical simulation, Pyramids, Solar energy, Solar radiation, Thermoclastism

\section{Introduction}

The pyramids of the Giza plateau were built oriented with the four compass points, using the sun or stars as guides. Originally, the walls were planned to be covered with high quality white limestone, but this outer surface was lost except for the cap of the Second Pyramid that is attributed to the Pharaoh Khafre. Another theory is that the Pyramids were built as stone steps for technical building purposes [1] or the suggestive idea that they constituted a stairway to the sky [2-4]. Whatever the reason, the external appearance is an enormous stone-work composed of several courses arranged as an enormous stair, with horizontal treads and vertical riser. In the lower courses, stone blocks are bigger; in the upper courses are smaller to make transport easier. For instance, in the Khufu's great pyramid, the lower stone blocks are sized $1 \mathrm{~m} \times 2.5 \mathrm{~m}$ and $1-1.5 \mathrm{~m}$ tall, and the upper $1 \mathrm{~m} \times 1 \mathrm{~m}$ and $0.5 \mathrm{~m}$ tall. Solar radiation hits the free surfaces of stone blocks, i.e. the top (horizontal) and one lateral side (vertical), except at the edges of the pyramid, or at the occurrence of gaps, where two or more lateral sides are hit. The stone blocks are mainly limestone, but lower quality, and some limy sandstone $[5,6]$. Temperature gradients inside the irregular material texture may be responsible of dangerous mechanical stress, worsened by the action of crystalization cycles of soluble salts. The synergistic effect of thermoclastism and haloclastism determine stone weathering, especially where the texture is weaker [7, 8]. The lower part is also affected by sand erosion [9]. In the long run, solar heating and cooling cycles may cause severe damage to stones that may fall down. At variable intervals, some fallen stone blocks have left gaps that break the continuity. The solar radiation is affecting the pyramid from 4,500 years, and will continue to do so for millennia. 
In this paper, a model simulation of the solar energy impinging on stone blocks is made to ascertain the impact of solar radiation on the pyramid walls, i.e. where, when and how much. The aim of this paper is to make a simu-lation of

\section{Materials and methods}

The model simulation has been made using the astronomical formulae that describe the daily and yearly apparent motion of the sun around the earth. They are based on the calculation of the solar declination, i.e. the apparent angle of the sun above or below the earth's equatorial plane, the height $\left(\mathrm{H}_{\odot}\right)$ of the sun above the local horizon, and the azimuth $\left(\mathrm{A}_{\odot}\right)$ computed as the angular distance between the meridian whose plane contains the sun and the vertical circle passing through the local south (i.e. the meridian of the observer) assumed as a reference, i.e. zero angle when the sun is

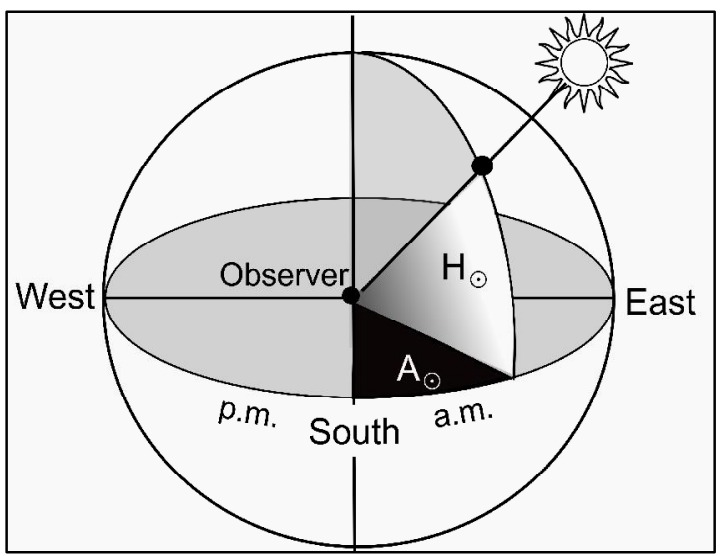

Figure (1) Shows the celestial coordinate system used to describe the solar motion, in terms of height $\left(\mathrm{H}_{\odot}\right)$ of the sun above the local horizon, and azimuth $\left(\mathrm{A}_{\odot}\right)$ from the sout-hern meridian. On the right side, time is a.m., on the left p.m.

\section{Results}

The solar radiation impinging on the selected surfaces has been calculated for the first day of each month, and the simulation has been made with 15 min resolution. The simulation has obtained the following results: *) the values of the solar height and azimuth calculated from 4:00 to 20:00, represent the height and azimuth of the solar disc. The time the solar radiation hitting the upper surface, and the vertical sides of differently oriented stone blocks located on the Pyramid walls in order to provide better interpretation of the temperaturerelated deterioration mechanisms.

at culmination, fig. (1). Time is expressed related to the so-called true astronomical time, i.e. referred to noon. The absorption of the atmosphere in reducing the intensity of the solar radiation and related energy is also considered as a function of the atmospheric optical mass crossed by the solar beams. The formulae are known in the literature and are presented and discussed elsewhere [10-17]. The model simulation will compute the instantaneous flux of solar energy and the daily total amount falling on the top of the stone blocks and on the vertical surfaces exposed to sunshine, fig. (2).

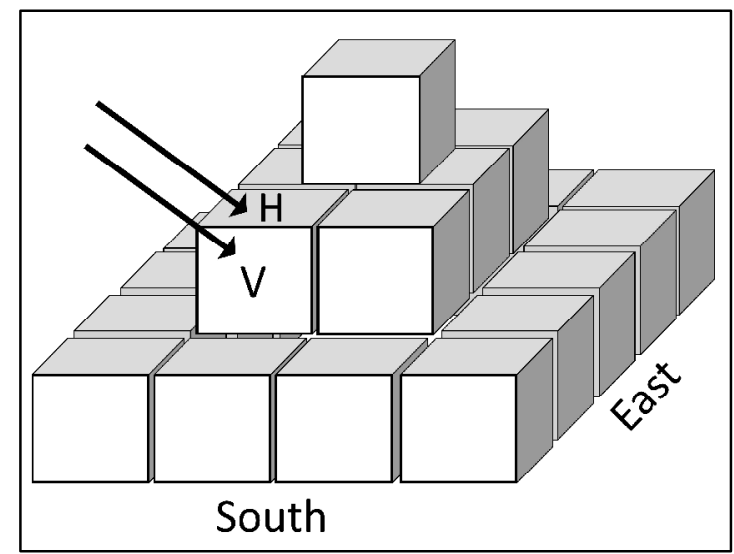

Figure (2) Shows the simulation of the solar energy impinging on the horizontal plane $(\mathrm{H})$ representing the top of stones and on the vertical surfaces $(V)$ exposed to sunshine.

when the sun is above the horizon is characterized by positive values of the solar height (i.e. daytime); negative values represent the nighttime. The results of the simulation are reported in fig (3).*) the daily total amounts of solar radiation (DTASR) have been calculated with high angular resolution for the period when the sun is above the horizon. For 
the high resolution, the polar plots can be applied either to simple structures with a few exposures (e.g. the Pyramids) or to structures exposed to all directions (e.g. the Sphinx). This variable, expressed in $\mathrm{kJ} \mathrm{m}^{-2}$, represents the density of energy, impinging on a vertical surface facing the sun. The results of the simulation are reported in fig (4). *) The instantaneous values of the flux of solar radiation
(IFSR) have been calculated with high temporal resolution for the period when the sun is above the horizon. This variable, expressed in $\mathrm{kW} \mathrm{m}^{-2}$, represents the instantaneous flux density of the energy impinging on the horizontal plane (i.e. the upper side of stones) and the vertical surfaces facing the four cardinal directions (i.e. the lateral sides of stones). The results of the simulation are reported in fig (5).
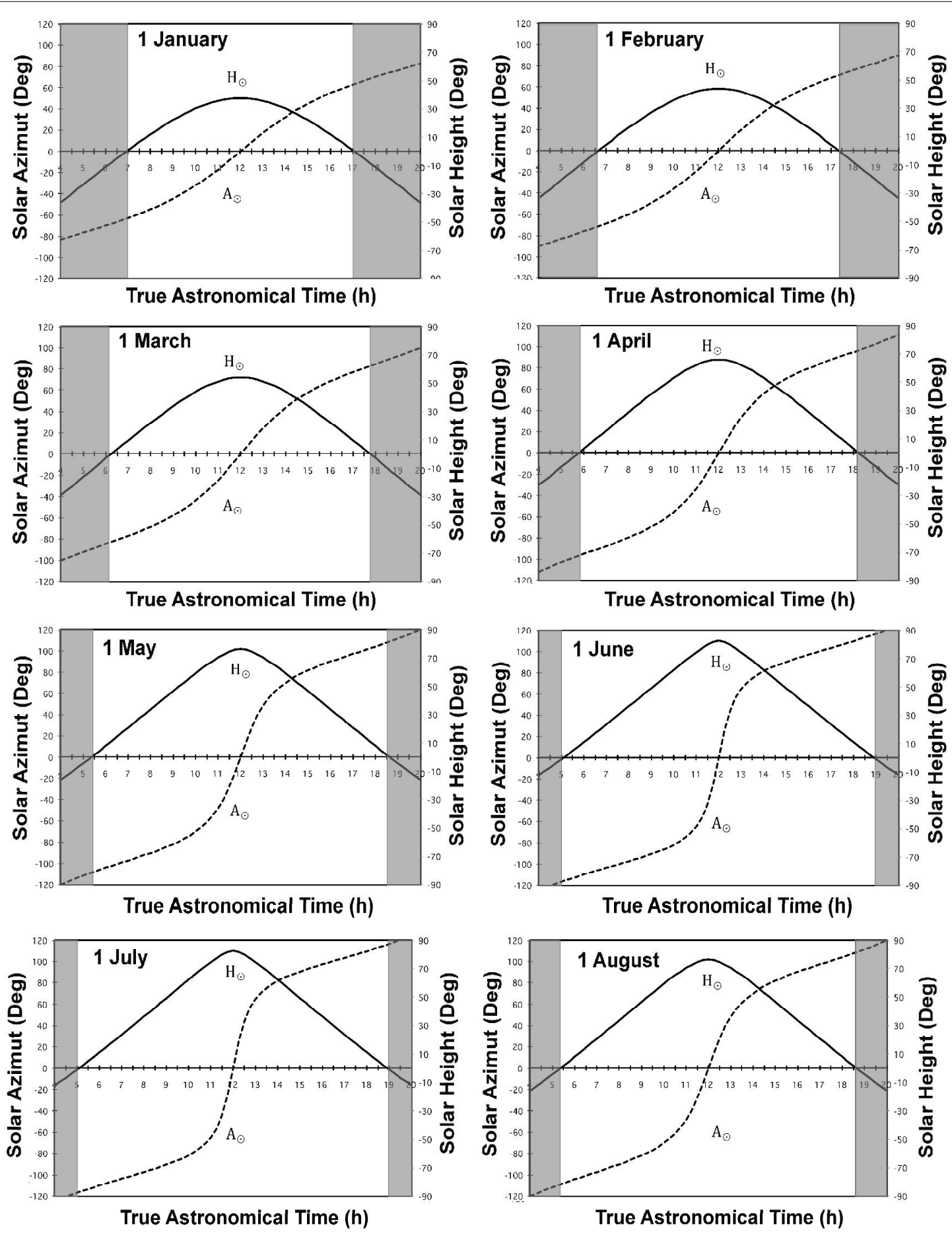


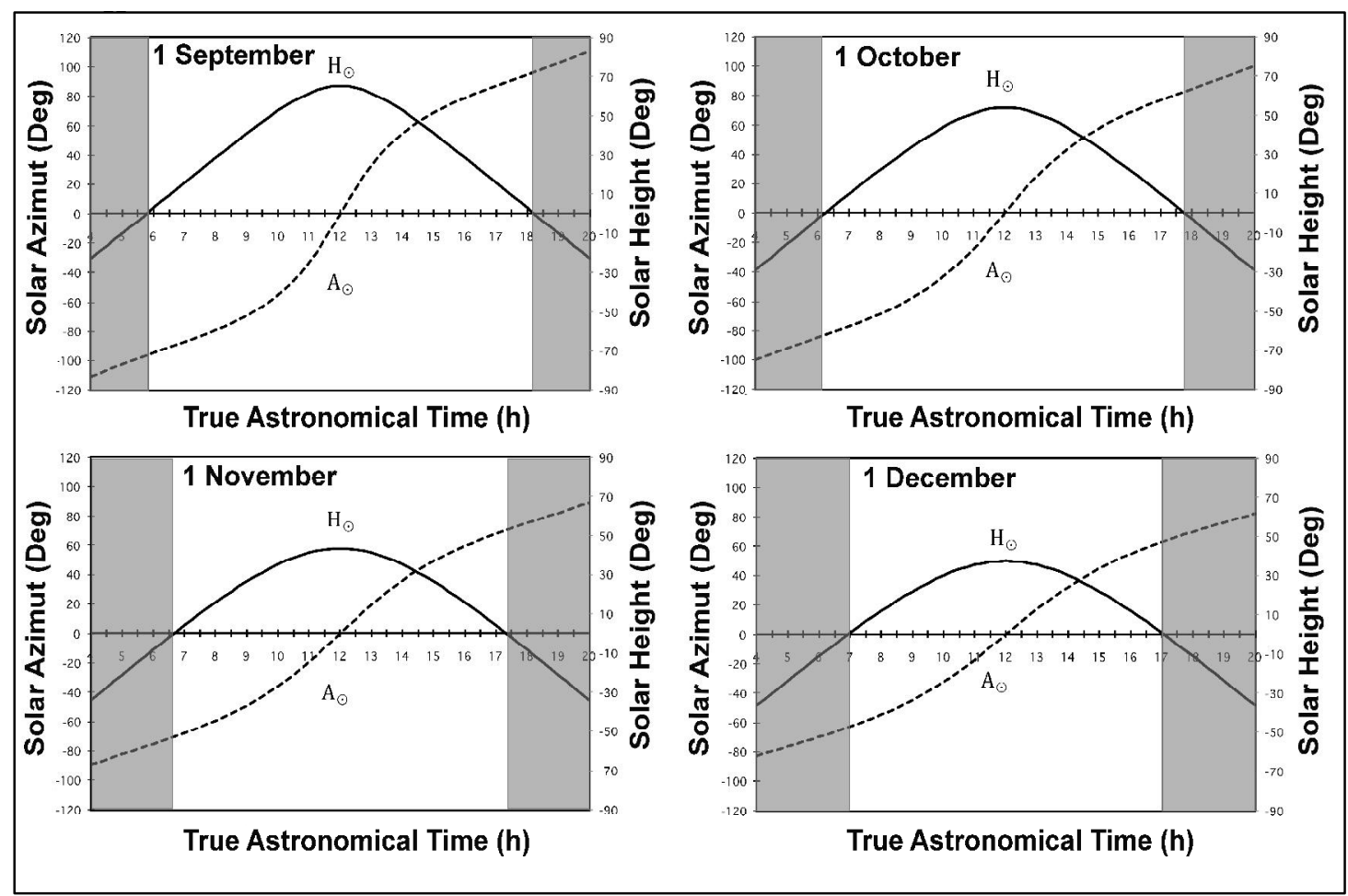

Figure (3) Shows the solar azimuth (Ao , dotted line) and height (Ho , thick line) during the day, calculated for the first day of each month. The nocturnal time, when the sun is below the horizon, is shaded.

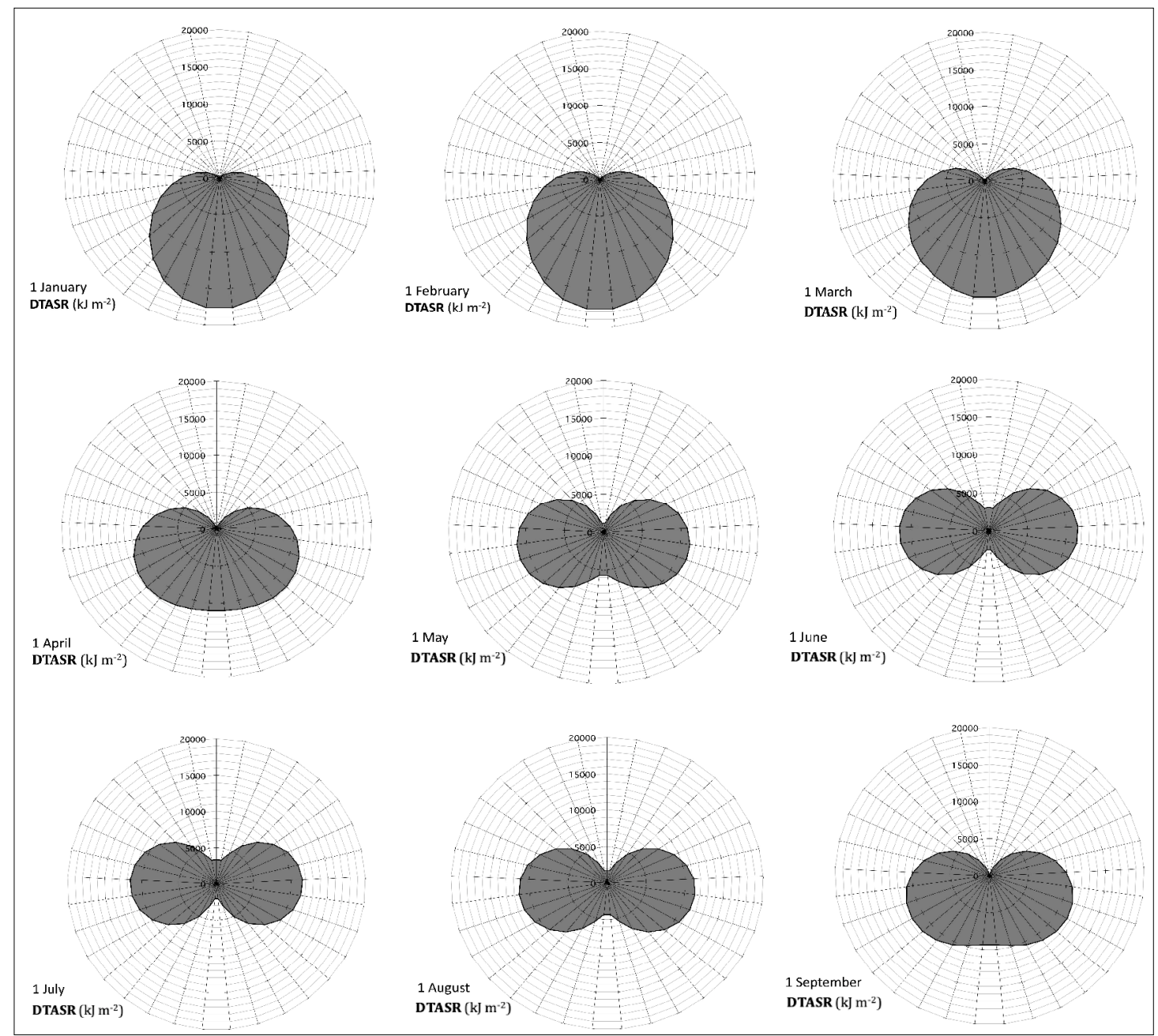




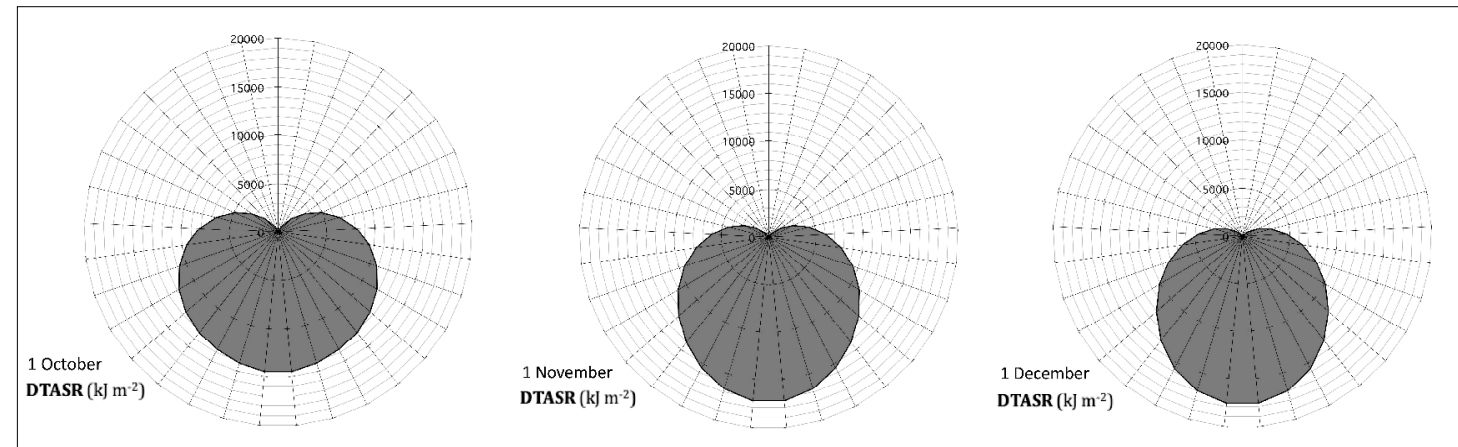

Figure (4) Shows the daily total amount of solar radiation impinging on a vertical surface facing the sun, calculated for the first day of each month. This plot applies to all directions.
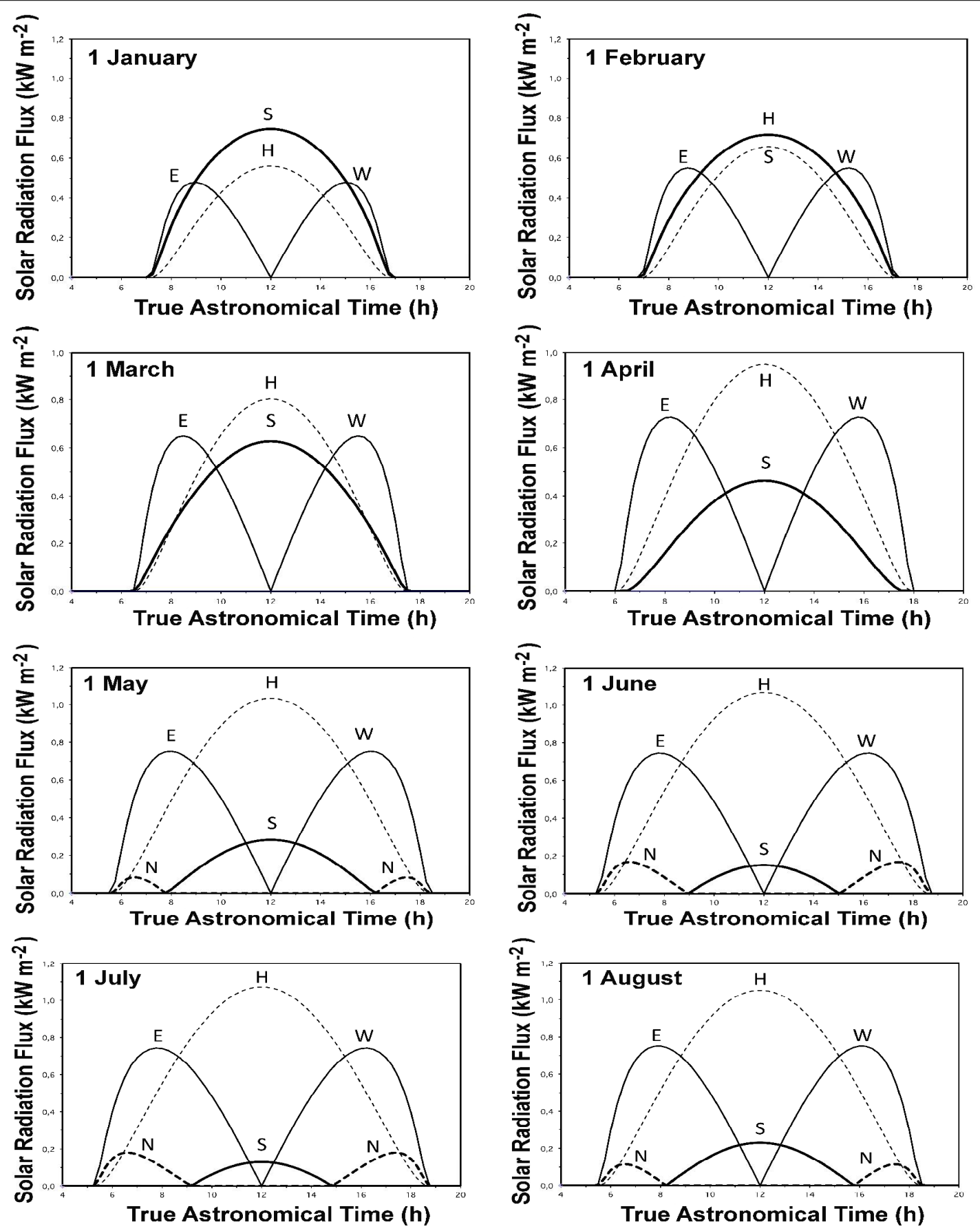

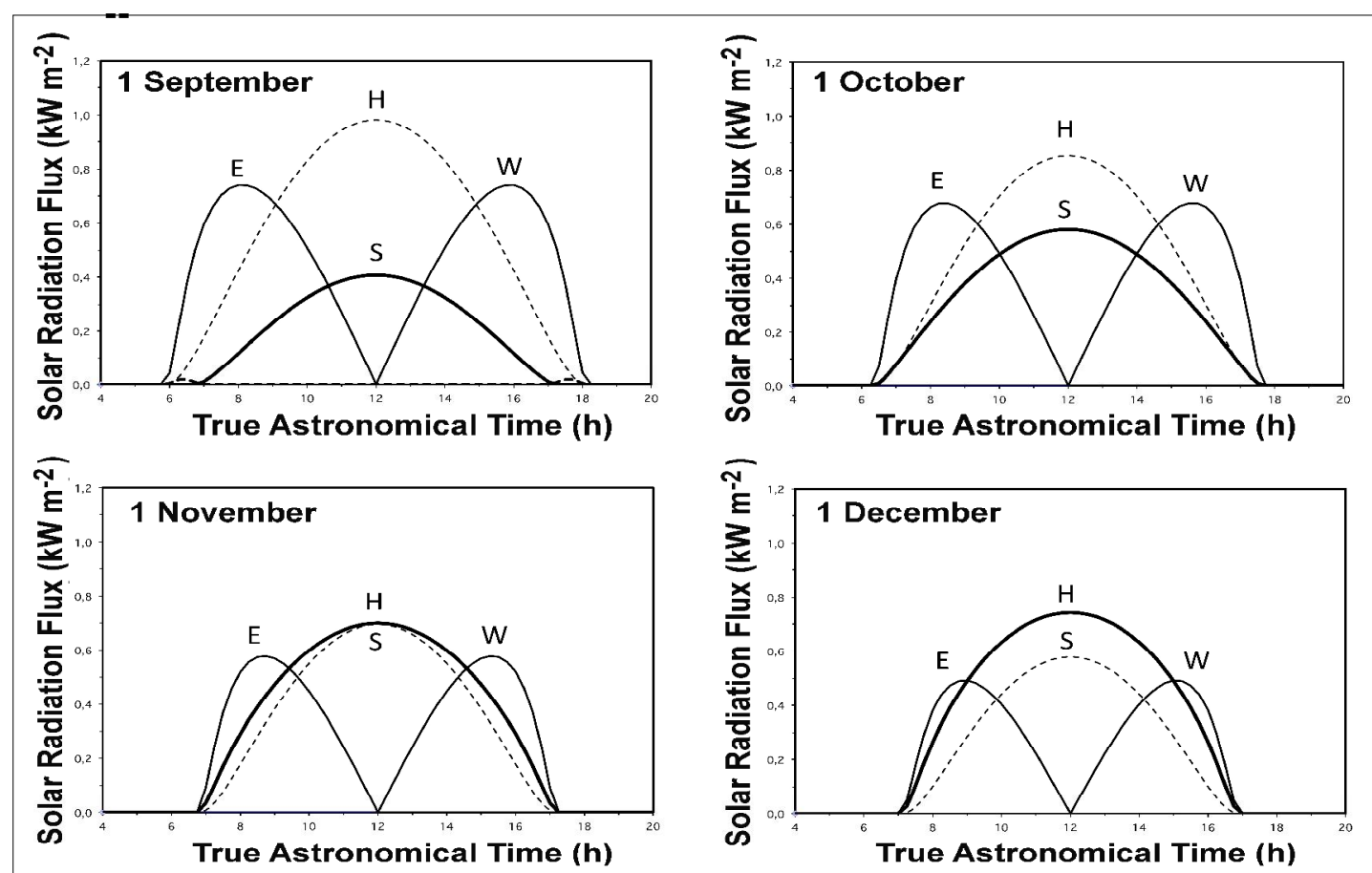

Figure (5) Shows the instantaneous values of the flux of solar radiation impinging on the horizontal plane $(\mathrm{H}$, thin dotted line) and the vertical surfaces facing the four cardinal directions ( $\mathrm{S}$, thick line: south; E, W, line: east and west; N, thick dotted line: north).

\section{Discussions}

Figure 3 shows that, during the calendar year, the sun at culmination (i.e. noon) at the summer solstice reaches the value $\mathrm{H}_{\odot}=83^{\circ}$ while at the winter solstice $\mathrm{H}_{\odot}=37.5^{\circ}$. At the summer solstice, the sun is in proximity of the zenith (i.e. $7^{\circ}$ to it), and the upper surface of stones is well reached by the solar rays, while they are almost grazing the vertical southern surface. As opposed, at the winter solstice, the sun is quite low, and the vertical southern surface receives more energy than the horizontal plane. One should consider that the vertical and the horizontal planes are hit in equal ways when $\mathrm{H}_{\odot}=45^{\circ}$. For the simple geometric features of the pyramid walls, aligned with the four cardinal points, the polar plots of figure 4 show that *) In winter DTAS reaches the maxi-mum values from the southern sector. *) In summer, DTASR has two maxima, symmetrically distributed from the eastern and western sector; the northern and southern sectors are similar, both with a minimum value.
The IFSR graphs in figure 5 indicate the following: *) The IFSR that hits the upper side of stone blocks exceeds all exposures for most of the year, except the middle of

winter. The highest IFSR values are reached in summer and decrease until they reach the minimum in winter. *) At noon, the maximum intensity of IFSR impinging on the upper side equals the radiation impinging on the vertical southern surface on $1^{\text {st }}$ November and $10^{\text {th }}$ February. In the winter period between these two dates, the peak of IFSR on the southern surface exceeds the peak on the upper side. *) The eastern and western sides receive the highest IFSR values in summer and minimum in winter. The minimum is in any case elevated, being some $2 / 3$ of the maximum summer value. Therefore, eastern and western sides receive a noticeable amount of solar energy during the whole calendar year. *) The southern side is the most heated surface in winter and the less heated one in July. The difference between these seasons is very high, the 
summer maximum being in proportion of $17 \%$ of the winter one. *) In June and July, IFSR impinging on the northern and southern exposures are almost the same, but distributed in different periods: on the northern side after sunrise and before sunset; on the southern side in the central part of the day.

\section{Conclusions}

The model simulation has clarified the solar energy impinging on the stone blocks of the Pyramids of the Giza Plateau. The horizontal surfaces, i.e. the top of blocks, receive the maximum energy in absolute terms. The southern surfaces undergo a strong seasonal cycle. They receive the maximum energy in winter and the minimum in summer. In summer, the energy amount on surfaces facing south is very small, similar to those facing north. The surfaces at the eastern and western exposures have also a seasonal cycle, but with limited changes in range. In summer, these two exposures reach the highest amount of radiation in comparison with the other vertical surfaces. The northern exposure is the less affected by solar income.

\section{Acknowledgements}

The author is indebted to Prof. Dr. Mohammed A. El-Gohary (Sohag Univ., Egypt) for having requested and stimulated this study.

\section{References}

[1] Fonte, G., (2007). Building the great pyramid in one year: An engineer's report, Algora Publishing, NY.

[2] Grinsell, L., (1947). Egyptian pyramids, John Bellows Ltd, Gloucester.

[3] David, R., (2014). Voices of ancient Egypt: Contemporary accounts of daily life, Greenwood, Santa Barbara, California.

[4] Smith, M., (2017). Following Osiris: Perspectives on the Osirian afterlife from four Millennia, Oxford Univ. Press, Oxford.

[5] Emery, K., (1960). Weathering of the great pyramid, Journal of Sedimentary Petrology, Vol. 30 (1), pp: 140143.

[6] Zalewski, F., (2017). Petrographic observations of the building stones of the great pyramid of Giza, Journal of Geological Resource and Engineering, Vol. 4, pp: 153-168.

[7] Chovdhury, A., Punuru, A. \& Gauri, K., (1990). Weathering of limestone bed at the great Sphinx', Environm. Geol. Water Sci., Vol. 15, pp: 217-223.

[8] Fitzner, B., Heinrics, K. \& La Bouchardiere, D., (2002). Limestone weathering of historical monuments in Cairo, Egypt, in: Siegesmund, S., Weiss, T. \& Vollbrecht, A. (eds.) Natural Stone, Weathering Phenomena, Conservation Strategies and Case
Studies. Geological Society, London, Special Publ-ications, Vol.205, pp: 217-239.

[9] Camuffo, D., (1993). Controlling the Aeolian erosion of the great Sphinx, Studies in Conservation, Vol.38, pp: 198-205.

[10] Robinson, N., (1966). Solar radiation. Elsevier, Amsterdam.

[11] Kondratyev, Y., (1969). Radiation in the atmosphere, Academic Press, NY.

[12] List, R., (1971). Smithsonian meteorological tables, Smithsonian Institution, Washington DC.

[13] Platridge, G. \& Platt, C., (1976). Radiative processes in meteorology and climatology, Elsevier, Amsterdam.

[14] Liou, K., (1992). Radiation and cloud processes in the atmosphere, Oxford Univ. Press, NY.

[15] Liou, K., (2002). An introduction to atmospheric radiation, $2^{\text {nd }}$ ed. Academic Press, London.

[16] Melnikova, I. \& Vasilyev, A., (2005). Short-wave solar radiation in the earth's atmosphere: Calculation, observation, interpretation. Springer, Berlin.

[17] Camuffo, D., (2019). Microclimate for cultural heritage, measurement, risk assessment, conservation, restoration, and maintenance of indoor and outdoor monuments, $3^{\text {rd }}$ Ed., Elsevier, NY (in press). 